\title{
A Review on the Concepts, Types, Aspects and Activation Factors of New Media Hooliganism
}

\author{
Young Nam Chung \\ Department of Sports Leisure, Sungshin Women's University, Seoul, Korea
}

Email address:

cyn21@sungshin.ac.kr

\section{To cite this article:}

Young Nam Chung. A Review on the Concepts, Types, Aspects and Activation Factors of New Media Hooliganism. Science Journal of Business and Management. Vol. 5, No. 5, 2017, pp. 199-205. doi: 10.11648/j.sjbm.20170505.14

Received: November 1, 2017; Accepted: December 20, 2017; Published: December 29, 2017

\begin{abstract}
The purpose of this study is to explore the concepts and aspects of hooliganism appeared in the new media. Behaviors in virtual spaces based on new media are actually linked to, supplement, and support behaviors in stadiums or on the street. The transformed complexion of hooliganism in traditional and real places (offline) is rising, and in spite of demands for more social concern, some regard this as merely the temporary hyperactivity of a minority of hardcore fans. There is also a predominate tendency to perceive certain relevant issues as momentary news items even when they are emphasized as social issues. In conclusion, in the new media environment, hooligans and hooliganism has been shown in a new aspect. It is possible to provide a suitable environment that hooliganism can be activated in cyberspace by New Media. In cyberspace hooliganism generates large amounts of information, such as video sharing and evolving the concept of violence to exercise a variety of bullying to a particular subject through various media. Due to these factors, hooliganism may appear to as universal and ubiquitous phenomenon. In particular, youth friendly and easily accessible cyberspace so that they likely to be involved in the hooliganism as in the case of British. Due to this new media environment hooliganism has been transcends time and space and it is becoming increasingly internationalized. In order to control new media hooliganism that is regarded to have a large ripple effect on individuals and society at large, other countries have already incited social concern on the subject and are implementing specific policy alternatives. The empirical and more deeply research are required in the meaning of establish a countermeasure for hooliganism in the new media.
\end{abstract}

Keywords: Hooliganism, New Media, Concepts, Aspects

\section{Introduction}

The features of new media are advancing between the mediums of television, internet, and mobile technology based on the union of computer and communication technologies. Recently, as the modality of media sports has transformed due to the advent of digital technologies, cable and satellite sport channels have emerged and the role of existing terrestrial broadcasting and relevant actors who once controlled sports broadcasting have been redefined, bringing about transformations in the dynamic between media and sports [19].

Sports organizations, the public, fans, supporters, including sports-related groups and operations, organizations, information exchange, and communication are transforming based on the new media environment. Producers and consumers, and teams and fans, for whom interactive communications is possible, recognize the advanced technologies of new media as an effective means of communication for communicating with one another and developing relationships, and are using new media in diverse ways [10]. The existing online community formed relationships based on the cafes and clubs offered in portal sites, but after the emergence of SNS this has transformed into spaces like Twitter's online groups where instant feedback is made possible [17].

There were 460 groups (June 30, 2011) for supporters of sports among the groups offered on Twitter (twittadwin://twitaddons.com). In a Naver search using the search term "sports" (March 18, 2016), 2,679 groups were introduced, including 4,932 on soccer, 11 on pro soccer, 68 on pro baseball, and 13 on red devils. There were also 17 groups on Kim Yeon-ah, and 14 on Son Hong-min in groups of fans related to particular sports stars. Furthermore, groups for sport 
fans and supporters are organized via the internet which is being used as an important space for communication. In 1995 the PC communication soccer club cyberspace became the starting point of the red devils, and the red devils were formally established in August of 1997 through internet communications. Today, the red devils take part in national team competitions, and when there are no competitions the red devils hold a variety of online and offline activities and events [9].

Cyberspace through new media provides an opportunity to encounter various forms of media, such as text, photographs, video and other visual images and audio contents. This makes transmitting and receiving more convenient and accessibility easy for users who are rapidly increasing. The contents offered through this have high authenticity, making their ripple effect significantly larger than traditional media [13].

In the new media environment, sports information can be simultaneously sent on high-capacity visual displays targeting the unspecified masses in a manner that transcends space-time This new media environment is providing suitable conditions in which hooligan groups can manage members, organize, and convert, and is serving the role of a pathway through which various forms of intangible violence are delivered. Internet sites made by soccer fans, whose interest and participation numbers are growing by the day, are spaces where it's possible to connect information exchange and interaction, as well as organization and actual behavior between site members. In this manner, modern information and communication technologies have made it possible for one to harass others through a variety of methods in a virtual space.

However, the internet, phones and social networks have become a primary medium for abusing others (nobullying.com/cyberbullying-examples, 2015. 5.19). As the internet, smartphones, and other new media usage increases, damage and acts of violence from the perspective of the general public, fans, and supporters are also increasing daily, and taking on diverse forms while producing mass victims. New media including newspapers, terrestrial television, and social media contribute to the expression of a violent culture and identity like hooliganism, and to the formation of those images. This new media is also providing a medium and space for the aggressive and violent behavior of supporters to take place.

$50 \%$ of the hate crimes, abuse against others, and displays of discontent related to soccer that occurred during the 2014 and 2013 soccer season took place through social media (http://backpagefootball.com/social-media-new-wave-footbal 1-hooliganism. For example, last season, Mario Barwuah, the AC Milan player who plays the position of striker, received 4,000 racially discriminating tweets and 8,000 tweets containing vulgarities. Because the anonymity of users is maintained by the personal information protection system, users can boldly carry out violent acts, and the majority of aggressors use social media as a sanctuary for alleviating their frustrations.

Also, Phil Neville, the head coach of Spain's Primera La Liga Valencia and former player, received organized threats of rape and murder towards not only himself, but his wife and cerebral palsy child from hooligans using social media. British authorities took these issues seriously and enacted laws regarding online abuse, and established an office to pursue aggressors to the end.

Behaviors in virtual spaces based on new media are actually linked to, supplement, and support behaviors in stadiums or on the street. The transformed complexion of hooliganism in traditional and real places (offline) is rising, and in spite of demands for more social concern, some regard this as merely the temporary hyperactivity of a minority of hardcore fans. There is also a predominate tendency to perceive certain relevant issues as momentary news items even when they are emphasized as social issues.

A portion of false, slanderous, and invective comments that rely on the anonymity of netizens lowers the internet's proper function and exert severe mental injury on the opposing team, athletes, and supporters. Malicious comments about other people is no different than 'comment hooliganism,' [5].

Generally, hooliganism refers to the chaotic, socially deviant actions of a group that brandishes violent acts against certain fans and groups, the players and fans of an opposing team, and disadvantageous calls during competition. Hooliganism is understood as malicious behavior against a team and players due to structural characteristics that entail competitiveness against an opponent. Hooliganism can appear in all sports activities and possesses a high probability. In a situation where hooliganism is explained as a global phenomenon, the nature and scope of limiting violent group behavior to supporters of soccer is complex.

New media hooliganism has a strong collective facet founded on new media, and refers to behavior patterns meant to damage or malign the opposition's reputation, and to disable them from normal activity by threats and intimidation [20].

After the hooliganism rooted in English society was raised as a serious issue in the $1980 \mathrm{~s}$, as visiting-team cheering became prevalent with the growth of transportation means, clashes between visiting-team fans and home-team fans became more frequent and began to come to the fore as a serious social issue [14]. Today, hooliganism has formed a mode of confrontation between athletes and supporters on both sides due to the competitive nature of sports, and has become a globally shared language due to the expansion of new media as a regular phenomenon [8].

Hooliganism based on new media transcends space-time and connects online and offline actions, and is expanding as a modality that mediates information. Internationally, hooliganism through new media is a daily phenomenon. Hooliganism based on new media doesn't involve direct physical violence, but there are numerous victims that take a multitude of different forms, and has become a serious social issue. At the present, there is a need for special interest and discussions on hooliganism that is evolving through new media[16].

On the one hand, now is the time to create a healthy netizen culture in which sports consumers who use new media are 
considerate of one another and respect each other's individuality. Furthermore, like the example of England which implemented 'online hooliganism guidelines', there is a need to refer to content that strictly regulates physical and mental abuse or intimidation, loss of property, and sexually and racially discriminatory messages directed at the players, supporters, and fans of an opposing team. Additionally, there is a need to make guidelines regarding contents that foment or allude to the type of regional discrimination that can take place in Korea.

In order to control new media hooliganism that is regarded to have a large ripple effect on individuals and society at large, other countries have already incited social concern on the subject and are implementing specific policy alternatives. In England, where hooliganism was a serious social issue, the 'Online Hooliganism Guide' (the Crown Prosecution Service: CPS) was applied from early 2013's World Cup semifinal match and continues to be in force today. This 'guide' prohibits by law the abuse of athletes on the field or online, behavior that threatens violence and the property of an opposing team's supporters, and discrimination against feminists, homosexuals, and people of color (http://www.theguardian.com/football/2013/aug/23).

There is growing concern over verbal abuse that occurs in cyberspace based on new media as internet and smartphone use increases, but studies on this matter are lacking. Since the violent actions of regular netizens, fans of certain athletes, and supporters are creating significant damage, there have been several studies overseas regarding sports violence through new media, and there has been a gradual accumulation of research outcomes. As a primary study on this subject, [4] analyzed the origins of soccer hooligans along with the current condition of hooliganism, and [12] studied evolving acts of criminal hooliganism from soccer fans. [16] in particular examined the Swedish website www.sverigescenen.com to analyze 3 types of identity including threatening behavior, violence, and masculinity, comparing hooligans and hooliganism of new media with traditional media.

Because studies in Korea on cyber and internet violence in general began in the early 2000s, today there are a considerable amount of research outcomes on the subject[3]. However, concern over new media hooliganism in the area of sports exist as only one phenomenon centered around particular sports news, and thus studies specifically on this matter both domestically and internationally are virtually non-existent.

In Korea's new media space that provides sports news or content, this kind of violence is increasing, but there has yet to be social concern or policy measures on hooliganism through new media that is linked with offline behavior, is organized, and that is evolving into diverse forms. Although there are also social concern and demands in Korean society to prevent and minimize the harmful effects of hooliganism carried out by sports netizens, fans, athletes, and supporters in the new media space, relevant studies are still in the introductory stage. Because there is also a lack of research outcomes there is first and foremost a need for an academic definition on relevant concepts and a social consensus process so that systematic discussions on this subject can take place.

In this manner, as use of internet, smart phones, and other new media increases, aggressors and damaging acts are growing daily from the perspective of the general public and fans who encounter sports news, and its forms are diversifying and producing significant victims. Accordingly, at the present more social concern is needed on this matter, and analyzing violent phenomena that take place in the cyberspace of new media related to sports, establishing a concept, and understanding these tendencies is a research task of urgent necessity.

This study considers the environment and concept of new media hooliganism that is being created, delivered, and expanded in new media, and classifies that facet based on this. This study also considers the complexion of hooliganism in the new media environment to develop a more systematic discussion on hooliganism based on new media that is taking on altered forms from existing hooliganism, more systematically conceptualizes these identities, provides baseline data for research in relevant fields, and contributes to the creation and growth of a healthy sports cheering culture.

\section{Concepts and Types of New Media Hooliganism}

This study reviews the concepts and types of new media hooliganism, and used foreign and domestic preceding research, government and private organization research reports, foreign and domestic internet data searches, newspaper articles, statistical data, and precedent cases to explore the identities of hooliganism. The results are as follows.

\subsection{The Concept of New Media Hooliganism}

The technological and social meaning of today's new media is being emphasized as a relative concept primarily concerning mass media as a medium. This is based on the union of computer and communication technologies, and the boundary between the two mediums is less clear than it was before. Among the writing revolution, printing revolution, and computerizing revolution, the new medium that has emerged from the computerizing revolution is akin to new media [21].

Recently, as the modality of media sports transforms with the emergence of digital technologies, cable and satellite sports channels have emerged and the role of existing terrestrial broadcasting and relevant actors who once controlled sports broadcasting have been redefined, bringing about transformations in the dynamic between media and sports. With this, the meaning of sports and media sports for consumers is understood and used in a form that differs from the past. Today, new media sports, or the internet, digital TV, and mobile sports is transforming to accommodate the schedule and demands of users as the role of the spectator and participant are combined.

Sports information can also be shared without limitation 
due to the influence of the internet. This means that the internet now occupies the role that TV once held. Live sports broadcasts provided through the internet can be edited and combined with other jobs. Also, scenes that one needs can be saved and printed out, and sharing evaluations and thoughts on matches can foster loyalty and involvement. In other words, the internet is evolving into a 'accommodating medium mechanism' in which users can actively and selectively participate in the broadcast[2].

In comparison with traditional media, the internet and other new media are generating a powerful image of hooligans, and delivering this to consumers. In this process, soccer supporters and hooligans zealously participate in visual display production, and by the function of "narrative stories" in traditional media advancing to a "narrative picture" function, new media's influence is growing and this new phenomenon is expanding internationally[16]. Social media is providing more versatile images, stimulating the behavior of supporters, and influencing them to invigorate themselves, but because there is no gatekeeper within the medium that chooses and censors images before they are sent out, it is easy to bully and issue threats in sporting events through Facebook and other social networks against supporters of the opposing team and referee calls that fans view as unfair.

Because there are many instances of cyberspace protecting anonymity, it can be easier than in real life to become exposed to violence. This is true of both aggressors and victims. Twitter users whose goal is to abuse and threaten athletes and supporters of opposing teams use social media out of their own frustration to abuse others, not simply because they like soccer. This is an act that may be considered criminal. Currently, although physical violence is becoming virtually eliminated at soccer stadiums that are under strict sanctions, acts of psychological violence via new media has given hooliganism a newly changed appearance.

The concepts of the term hooligan include individuals who 'collectively' carry out disturbances on the premise of support for a certain team or athlete. In addition to this, a cyber-hooligan is one who moves the location of group disturbances from the stadium to cyberspace. Cyber hooligans exert influence with the goal of cyberspace users who sympathize with their desires to emphasize or achieve their assertions in order to resolve issues on certain subjects. When these kinds of collective actions violate the law and possess illegal purposes, they can be classified as hooliganism, not as cyber protests [11].

Despite the various definitions of hooliganism, the common substance until now is the carrying out of violence, and recently hooliganism is evolving into a concept that depicts various forms of violence against particular targets through the medium of new media which can generate and share mass information. The frequency of use and influence of new media among teens and those in their twenties is vastly larger compared to other generations, and this has a substantial influence on their behavior.

Media hooligans, as a relative concept of offline hooligans, refers to group disturbances that have been moved from the stadium to cyberspace. Cyber hooligans exert influence with the goal of cyberspace users who sympathize with their desires to emphasize or achieve their claims in order to resolve issues on certain subject. When these kinds of collective actions violate the law and possess illegal purposes, they can be classified as hooliganism, not cyber protests [11].

As stated earlier, the characteristics of hooliganism include a strong collective facet founded on new media, and refers to behavior patterns meant to damage or malign the opposition's reputation and to disable them from normal activity by threats and intimidation. There is also a facet in which behavior in virtual spaces is linked to behavior in the streets or stadiums. This can be called the altered complexion of hooliganism in new media.

\subsection{Types of New Media Hooliganism Based on Content}

The image of hooligans being delivered to the public through new media reinforces their identity, with violence as an important substance and supporter violence becoming specialized. Additionally, hooligan culture performs the function of verifying various types of masculinity, and these types of violent hooligan acts are also branded as behavior in an ethical state of panic [16].

Today, cyberspace can certainly be used as a means to harass others, and it has become possible to gradually drive others to death. The types of acts that inflict bullying on others in regular cyberspace can be segmented into the following categories based on the content.

Cyber Stalking - In cyber stalking, the goal of sending messages is to threaten or cause fear in others. The recipient of these messages begins to worry about their safety and leading a regular life.

Humiliation/Degradation - Media hooliganism refers to the act of using cyberspace with the goal of damaging the reputation of a target by spreading rumors and hearsay.

Taunting - Taunting refers to the unceasing transmission of vulgarities and threatening or harassing messages through the internet or phone.

Impersonation - This is the act of falsely pretending to be the opposing target with the goal of harassing them and damaging their reputation. It is also when an individual generates a false identity and profile and behaves as if they are their target. This leads to numerous people around the target misunderstanding them.

Malicious Comments - This refers to the act of harming a target by being hostile, rude, and using vulgar and violent language with the purpose of causing a fight with a target.

Text Messages - As the most universal type for alienating others, this is the act of unilaterally or aligning with others to emotionally harass a target by sending them unceasing text messages and accruing fees for incoming messages.

Password Theft - A portion of aggressors make all possible attempts to acquire the passwords of victims. After procuring a password, aggressors enter the sites of their victims and cut them off or share this with other friends.

Generating Websites - This refers to making a website or page and uploading pictures or text with the goal of harassing 
and belittling a target.

Using Pictures and Images - This refers to posting embarrassing pictures of the victim via the internet with the purpose of harassing and belittling a target. In most instances, these types of pictures and images are fake or altered to depict the victim. As an example, using a picture and image like this with the purpose of spreading a rumor that the victim sent nude pictures of themselves to a person they met online.

PC Attacks and other Hacking - This is the act of an expert or someone with abundant computer knowledge sending Trojan horses, viruses, worms, and spyware to someone else's computer. For example, the rage over lines in the US comedy talk show of Jay Leno during the 'Ohno incident', and knocking down of the US broadcast station's website would fall under this.

Proxy Attack - This refers to installing a proxy on the computer of a victim to gain access to most of their confidential information with the goal of causing them humiliation or emotional damage. The aggressor uses this information to insult or threaten the target.

Firm Action - When another user posts to a virtual space the violent expressions of an individual who first instigates violent behavior via cyberspace or the internet, this can be viewed as an act that falls under the requisites of a crime as internet acts of violence may occur (Jong, 2011).

\section{Concepts Similar to Media Hooliganism}

Cyber hooligan: As SNS (social networking service) users rapidly increase, there have been users who engage in fanatical behavior on the level of mayhem by hurling vulgarities and slander on sites like Facebook. These individuals are known as cyber hooligans, and are a concept similar to SNS hooligans and internet hooligans.

Cyber terror: As a term pointing to large-scale violent acts using cyberspace where computer communication networks are built, this generally refers to the criminal act of using a computer communication networks to break into the information systems of a government or private agency, and causing serious obstacles or destruction (Naver.com, Open Dictionary, 2003.11. 14).

Cyber Bullying: This refers to those on the receiving end of attacks or insulting remarks via email, chat windows, blogs, websites, news boards, and other internet spaces and cell phone text messages, or those who suffer psychological or physical damage due to the circulation of pictures or content meant to cause offense. For example, malicious comments, unwanted pictures circulating around Cyworld, and receiving verbal abuse would fall under this [7].

Netigen: Netigens is a concept similar to media hooliganism. Netigen is a compound word of netizen and hooligan, and refers to people on the internet who unconditionally support or criticize a particular group. This concept points to people on the internet who unconditionally support or criticize a particular group or issue through aggressive and extreme comments on the internet. This is a word that was made alluding to hooligans in Europe who incite disturbances depending on whether their soccer team wins or loses a match. [Naver Jisik Encyclopedia] Netigan [netigan].

Message boards are full of malicious slander and vulgarity from numerous visitors, and netigens who contribute to instances of people ending their lives due to hurt from criticism are referred to as "akpul jok" and "internet hooligans".

Cyber bullying

As a term related to cyber violence, cyber bullying is the most universally used term overseas. Cyber bullying refers to the act of harassing other using email, instant messages, text messages, digital image transmission, web blogs, chat rooms, and other information instruments [1], [15]. [19] also view the act of purposefully attacking other people online as cyber bullying. This includes sending harmful and cruel comments or pictures to others.

\section{Factors for the Invigoration of New Media Hooliganism}

New media specializes the violence of team supporters, and has more influence than traditional media. While traditional media unilaterally transmits text, letters, and images, new media has made multilateral communication possible based on the development of broadcast communications. In new media, users can exchange various materials with one another as the medium transcends space-time with simultaneity, and where large-scale images can be sent without censorship. This has a vastly larger influence on the attitudes of users than traditional media.

\subsection{Cyberspace Generation}

New media is a term that explains the communication relationship that a computer network forms. It generates a cyberspace which enables the virtual activities of hooligans and is a factor that is invigorating this type of activity. Computer networks, differing from communication methods up until now, possess characteristics that are asynchronistic, multi to multi communication, and bidirectional. This type of psychological and social space formed by these unique characteristics is called cyberspace (Kookhak Data Center, 2006, Naver Jisik Encyclopedia).

The physical concepts that should exist in original space are not contained in cyberspace, and the without the intervention of the human body people carry out all manner of acts that they would in real life. What takes place in cyberspace verifies virtual experiences and social relationships. Cyberspace allows one to experience virtual reality, and continuous repetitive exposure to it has the effect of one being unable to discern reality, causing them to perceive reality and virtual reality as equivalent concepts. Also, cyberspace allows humans to feel as if they are in environments that would be difficult to experience in daily life by manufacturing those 
environments without the human directly experiencing them. Recently, screen golf, virtual horse riding, virtual airplane operation, and other virtual realities have advanced into special spaces where one uses their entire body.

\subsection{Increase of Irresponsibility Due to Non-Face-to-Face Communication}

The largest characteristic of cyberspace through new media may be its non-face-to-face communication. Non face-to-face communication refers to a method of exchanging information using symbols or language without seeing the opposing side's face [11]. The formation pattern of the non-face-to-face communication relationship in cyberspace increases the convenience of expression and decision-making between hooligans, and is also the cause of irresponsibility regarding extreme expressions and violent behavior in cyberspace. Also, facts that have been generated and unverified in cyberspace from the non-face-to-face characteristics are easily accepted, dispersed, and agreed with at an extremely fast speed. When collective assault due to this takes place, victims may be harmed and have their reputations instantly damaged.

\subsection{Simultaneity That Transcends Time-Based and Spatial Limitations}

Cyberspace through new media is unaffected by the limitations of time and space, and the providers and recipients of information can engage in information exchange. The simultaneous transmission and reception of information is possible worldwide, and the majority its users can use cyberspace everywhere. Now, hooligans can instantly disseminate information through a networked structure of information delivery in a virtual space composed of the web that is globally spread. The space for hooligan group activity is expanding, and it is possible now for them to coordinate a particular time to conduct organized activities.

\subsection{Openness Accessible to Everyone}

Cyberspace through new media is an open space accessible to everyone regardless of population or social background. Information transmitted in cyberspace is unaffected by time and space, and anyone can access this information. The scope and limitations of that influence is difficult to measure. Youth, in particular, are the primary users of cyber networks via the internet, and they have an underdeveloped ability to discern danger. There is a high possibility that certain information they are exposed to may be accepted. The rise of instances in England recently where those in their teens and twenties are becoming hooligans and violating positive laws may be a result of perversely acquiring information in these types of cyberspaces (England BBC broadcast, 2010, Oct. 8).

\subsection{Multidirectional Interaction}

New media has made the multidirectional interaction of the medium possible. On the new media platform, receivers are not simply passive beings accommodating the information of senders, but are beings who perform the role of making networks and messages into a progressive form. Because computer communication networks are open to everyone, anyone can perform the role of a producer of information by posting their opinions and assertions. And through interactions between people who do not know one another, computer communication networks have made it possible for users to form groups and plot collective criminal acts, and continuously carry out this behavior. Interactions in new media allow social actors to experience the processes and methods related to face-to-face meetings. People use and interpret symbols through interactions, deliver ideas to one another, make impressions about the other person, have self-consciousness, and construct a world where they actually experience social situations (Institute of Sociocultural Research, 2000, Naver Jisik Encyclopedia interaction). A social structure exists in cyberspace as well through personal interactions, and a society does not exist without individuals.

\subsection{Anonymity for Securing Identity}

Differing from everyday spaces, in cyberspace the public are unaffected by the confines of behavior since their identities and names are not revealed to others. Anonymity from the aspect of freedom of expression means that one is able to express their opinions without hesitation [2]. Anonymity is becoming suitable grounds for hooligans to participate in cyberspace and engage in violent and irrational behavior. In everyday life, many innormative and antisocial impulses are suppressed because of fear of interruption or punishment, but in cyberspaces through new media, anonymity can free one from general suppression and provide opportunities to engage in atypical behavior. This is a factor that allows the generation and activity of hooliganism.

\subsection{Ease of the Provision of Information}

Cyberspace is a factor that can invigorate hooliganism. Through simple actions and processes aggressors can post, erase, or alter information containing their intentions. Cyberspace has an ease in the provision of information. In cyberspace, the internet is a basic means of communication where an action as simple as a click can harm another person. This virtual space provides an environment where violent behavior can occur much faster than in the real world. Hooliganism using a computer differs from crimes in live spaces because aggressors post information in a virtual space using a computer and lack criminal awareness or evasion judgement, which becomes a factor that makes aggressors less perceptive and sensitive of the seriousness of a problem.

\subsection{Increased Ripple Effect Due to Video}

Lastly, cyber space through new media is a space where text, pictures and other visual images, audio contents and video, and other diverse forms of information can be accessed by the public. With the development of information communication technology, the transmission and reception of large videos has become easier with a higher degree of accessibility. Users are rapidly increasing, and because of the high characteristic 
authenticity, its ripple effect is much larger than other forms of data. Videos provide scenes that are gruesome or have a high level of violence, and users who encounter this have a weakened power of discernment from reality. This can cause the same criminal acts to take place in reality. This ripple effect in cyberspace suggests that media hooliganism has a relatively higher potential to occur among the younger generation who have easy access to information than it does among other generations.

\section{Conclusion}

This study was carried out to review to the concepts and appearances of hooliganism in the new media environment. The conclusion regarding this subject is as follows. Hooligans and hooliganism in the new media environment are emerging in a new appearance. This makes it possible for new media to provide a suitable environment where hooliganism can become invigorated in cyberspace. Hooliganism in cyberspace generates and shares video and other large scale information, and is evolving into a concept that carries out various forms of violence against particular targets through various mediums. Additionally, modern hooliganism uses virtual spaces provided in the new media environment as a pathway to substitute, support, and prepare real life situations, manage members, and disseminate information for collective behavior. Through this, hooliganism is emerging as a universal and ubiquitous phenomenon. Like the examples of England, cyberspace is youth-friendly and easy to access, and due to this there is an increased potential for them to become involved in hooliganism. Furthermore, due to this environment that transcends new media space-time, hooliganism is gradually becoming internationalized. In the context of establishing countermeasures, more in-depth and empirical studies on hooliganism in the new media environment are needed.

This work was supported by the Ministry of Education of the Republic of Korea and the National Research Foundation of Korea (NRF-2017S1A5A2A01025065)

\section{References}

[1] Belsey, B: Cyberbullying: An emerging threat to the "always on" generation. From http://www.cyberbullying.ca, 2006.

[2] Choi Byeong-ho: Examining TV Sports Journalism. Honggyeong Publishing, Seoul, 2003.

[3] Doo Kyeong-hui, Kim Kye-hyeon, Jeong Yeo-ju: Trends and Tasks of Cyber Violence: the definition and types of cyber violence. Counseling Studies, 13(4), 1581-1607, 2012.

[4] Ingle, Sean: When did football hooliganism start? London: The Guardian, 2006.

[5] Jang Dal-yeong. 2014. 08. 13. [Jang Dal-yeong's LAW\&S] Corrupt Ruling by Money?' A female in her 30s who uploads slanderous posts towards Son Yeong-jae, monetary penalty, Journalist Min Ung-gi. Sunday Paper online article (2015. 11.24).

[6] Jeong Jeong-won: A Study on Regulations of Internet Defamation: focusing on criminal law regulations, Hanyang University Graduate School., 2011.

[7] Jeong Yeo-ju, Kim Dong-il: Harmful Experiences of Youth Cyber Violence and Emotional Regulation. Counseling Studies, 13(2), 645-663, 2012.

[8] John H. Dunning: The eclectic paradigm as an envelope for economic and business theories of MNE, International Business Review 9, 163-190, 2000.

[9] Kim Young-gap: A Cross-Cultural Approach of the Red Devils and Hooligans. Korean Sports Academic Journal, 45(4), 49-59, 2006.

[10] Korea Institute of Sports Science: White Paper on the Sports Industry, 2014.

[11] Lee Hyang-gi: A Study on Defamation in Cyberspace. Kyeongsang University Graduate Thesis, 2007.

[12] Matt Hopkins \& James Treadwell: Football Hooliganism, Fan Behaviour And Crime: Contemporary Issues, London; New York: Palgrave Macmillan, 328, 2015.

[13] Park Yu-jin: A Study on Characteristics of Malicious Posts in the Cyber Community. Hanyang University Graduate School MA dissertation, 2012.

[14] Geoffrey Pearson: Hooligan: A history of respectable fears Paperback, Palgrave; 1st edition, 1983.

[15] Patchin, J. W., \& Hinduja, S: Bullies move beyond the schoolyard: A preliminary look a cyber bullying, Youth Violence and Justice, 4(2), 148-169, 2006.

[16] Radmann, A: New Media and Hooliganism, 8th European Association for Sociology of Sport (eass). People in motion bridging the local and global. Umeå, Sweden, 18-22 May, 2011.

[17] Realistic Culture Research: Popular Culture Dictionary, Naver Jisik Encyclopedia, 2009.

[18] Sim Hong-jin, Hang Yu-seon: A Study on the Usage Motivation of Micro-blogging. Focusing on Twitter. Korean Broadcasting Bulletin, 24(2), 192-234, 2010.

[19] Ybarra, M. L: Linkages between depressive symptomatology and Internet harassment among young regular Internet users. Cyber psychology and Behavior, 7(2), 247-257, 2004.

[20] Young-nam Chung.: Media Sports. Korean Media, Seoul. 2008.

[21] Young-nam Chung: A Review of the Concepts and Complexion of Hooliganism in the New Media Environment, Korea Social Sports Journal, 63, 275 288, 2016.

[22] http://www.theguardian.com/football/2013. 8. 23.

[23] http://backpagefootball.com/social-media-new-wave-footballhooliganism/97197/. 2015. 11. 28. 